Fournal of African Law, 46, 2 (2002), 259-269 (c) School of Oriental and African Studies. DOI: $10.1017 /$ S0221855302001931 Printed in the United Kingdom.

\title{
GOMMENTS
}

\section{Going it Alone? SADG Declarations and the Gender Debate}

The debates surrounding both the content and interpretation of human rights have always been contentious. It seems that the points of difference between countries, including those on the African continent, ${ }^{1}$ are such that consensus on the content of human rights is difficult if not impossible to reach. Perhaps the time has come to move away from "one size fits all" initiatives. Short of abandoning human rights altogether, heresy in this day and age, perhaps we should seek consensus amongst smaller groupings of states, hence the suggestion made here that the countries of the Southern African Development Community (SADC) should go it alone. Indeed one could argue that the process of going it alone has already begun. In gender issues that has been achieved in SADC by way of two Declarations, the first the 1997 SADC Gender and Development Declaration and the second the 1998 Addendum to the Declaration on Violence Against Women. Before examining the provisions of the two declarations, it is as well to give a brief background to SADC.

SADC comprises 14 countries, namely Angola, Botswana, Democratic Republic of Congo, Lesotho, Malawi, Mauritius, Mozambique, Namibia, South Africa, Seychelles, Swaziland, Tanzania, Zambia and Zimbabwe. It was formed in Lusaka on 1 April 1980 and was originally known as the Southern African Development Co-ordination Conference (SADCG). At its formation there were nine member states. In 1992 a meeting was held in Windhoek, Namibia which led to the signing of the Declaration and Treaty which established the Southern African Development Community. The objectives of the Community include poverty alleviation, employment creation, the promotion of self-sustaining development through self-reliance and interdependence of member states. The SADC Treaty also provides that the community seeks to "evolve common political values, systems and institutions" and "to strengthen and consolidate the long-standing historical, social and cultural affinities and links among people of the region".

Given the diversity of countries within the SADC grouping, this is indeed a tall order. The countries range from the very small, in terms of population, like Namibia, to the very large like the Democratic Republic of the Congo (DRC); from economically strong countries like Botswana and South Africa to some of the poorest countries in the world such as Mozambique, Malawi and increasingly Zimbabwe; from post-socialist states like Tanzania to aggressively capitalist states like South Africa; and from conflict-ridden Angola and the DRC, to peaceful Mauritius and Seychelles. However, although many things divide the states, there is much that unites them, not least the position of women. In all SADC countries women are, relative to men, disadvantaged, socially, economically,

\footnotetext{
1 See the debates around the Draft Protocol to the African Charter on Human and Peoples' Rights on the Human Rights of Women, Addis Ababa, 13 September 2001, CAB/LEG/66.6.

2 As quoted in SADC Gender Monitor (1999) at 44.
} 
culturally, politically and legally. This despite the fact that article 6(2) of the SADC Treaty prohibits discrimination on the basis of sex.

SADC countries have shown a formal commitment to gender equality in that all of them except Swaziland have ratified the Convention on the Elimination of All Forms of Discrimination Against Women (CEDAW). ${ }^{3}$ Indeed the SADC bloc was influential in getting the Optional Protocol to CEDAW ${ }^{4}$ adopted. During Namibia's presidency of the Security Council it helped to push through Security Council Resolution 1325 on Women and Peace and Security. ${ }^{5}$ All SADC countries have ratified the African Charter on Human and Peoples' Rights $1981^{6}$ together with the UN Convention on the Rights of the Child, $1989^{7}$ and many have ratified the African Charter on the Rights and Welfare of the Child, $1990 .{ }^{8}$ Still there appears to be a gap between promise and practice. Reasons for this are many. Ongoing civil wars in Angola and the DRC mean that all but the elite are subject to poverty and deprivation. The AIDS pandemic is having a monumental impact on the economies and populations of the entire region. Where women's rights are concerned, there is of course the barrier of the broadly defined "culture" which is often put forward as the reason for their inferiority of treatment. This leads us to the SADC Declaration on Gender and Development of 1997 and the Addendum to the Declaration on Violence Against Women of 1998.

The Declarations have their roots in the Beijing Declaration and Platform for Action. ${ }^{9}$ Returning from the Beijing Conference, women from the SADC region, from both the governmental and non-governmental sectors, determined to make real the 12 points of action identified in Beijing. To this end, the task force that had been set up by women from the government and NGO sector to prepare for Beijing, was transformed into a Regional Advisory Committee after the conference. ${ }^{10}$ Working with this Committee, the SADC Council of Ministers "adopted a policy and institutional framework for gender mainstreaming"." Seven months later in September 1997 the SADC group adopted the SADC Gender and Development Declaration.

This Declaration is a synthesis of the Nairobi Forward Looking Strategies, ${ }^{12}$ CEDAW and the Beijing Declaration and Platform for Action. It provides that gender equality is a fundamental right ${ }^{13}$ and that SADC member states by virtue of the non-discrimination provision in the founding treaty of SADC ${ }^{14}$ undertake not to discriminate, inter alia, on the basis of gender. The preamble to the

\footnotetext{
3 Convention on the Elimination of All Forms of Discrimination Against Women, 18 December 1979, 1249 UNTS 13.

4 Optional Protocol to the Convention on the Elimination of All Forms of Discrimination Against Women reproduced in P. Ghandi (ed.), Blackstone's International Human Rights Documents, 2nd ed., London, 2000, 103.

5 SC Res. 1325, 2000.

6 African Charter on Human and Peoples' Rights, 1981 reproduced in 21 ILM (1982) 59.

7 Convention on the Rights of the Child, 20 November 1989, GA Res. 44/25.

8 African Charter on the Rights and Welfare of the Child, adopted July 1990, OAU Doc.CAB/ LEG/TSG.Rev.1.

9 Beijing Declaration and Platform for Action, 15 September 1995 reproduced in 35 ILM 404 (1996).

10 SADC Gender Monitor (1999) at 1.

11 Ibid.

12 Forward Looking Strategies for the Advancement of Women to the Year 2000, UN Doc. A/ CONF.116/12, 1985.

13 SADC Gender and Development Declaration 1997, Bi.

14 SADC Treaty article 6(2).
} 
Declaration also notes that in SADC countries: "Gender is an area in which considerable agreement already exists and where there are substantial benefits to be gained from closer regional co-operation and collective action". To this end the Declaration makes provision for mainstreaming gender concerns within the work of SADC. ${ }^{15}$ SADC countries then pledge to focus on women's interests in the socio-economic, cultural and civil and political fields. This remit includes achieving a 30 per cent target of women in political and decision-making structures by the year $2005 .^{16}$ South Africa is the only country that has so far met this target. There has however been increasing recognition of the need for affirmative action policies to redress the imbalance which have been introduced in Angola, Namibia, South Africa, Tanzania and Zimbabwe. The measures, however, "will only be effective if they are enforced and women are provided with the skills to hold public office". ${ }^{17}$ The SADG governments also undertake to promote women's access to productive resources such as land ${ }^{18}$ and formal employment as a way of reducing poverty ${ }^{19}$ and to enhance women's access to education and health facilities. ${ }^{20}$ The issue of land ownership is an important and contentious one. While countries pledge to give women access to land in their own right, few deliver. ${ }^{21}$ Those meeting their obligations include Tanzania which has passed a Land Act giving women the right to own land. ${ }^{22}$ However, there are sometimes conflicts between statutory provision and customary practice so that in Lesotho for example: "The Land Act of 1979 . . is gender-neutral in its provisions. The practice of allocating land to married men, especially in the rural areas, is based on customary attitudes and practices." ${ }^{23}$ The gains made by women at the population conference held in Cairo in $1994^{24}$ are reflected in the list of State obligations to recognize, protect and promote not only the reproductive rights of women and girls, but also their sexual rights. ${ }^{25}$ This is an important pledge particularly for women in countries like Mauritius which has a high rate of back-street abortions because of the illegality of abortion in the country. ${ }^{26}$

Picking up on article 18(2) of the African Charter, the SADG Gender and Development Declaration enjoins states to promote the human rights of women and children. In order to facilitate this, the "mass media is to disseminate

\footnotetext{
15 SADC Gender and Development Declaration, 1997, Fii.

16 Ibid., H(ii).

17 SADC Gender Monitor (1999) 13.

18 Women and Law in Southern Africa Research Trust (WLSA) (2001) A Critical Analysis of Women's Access to Land in the WLSA Countries. See also A. Ngwala, "The new Land Acts in Tanzania and women's access to land rights", in J. Stewart and S. Mvududu (eds.), WLSA Colloquium Papers, forthcoming.

19 SADC Gender and Development Declaration 1997, H(iii).

20 Southern Africa Research and Documentation Centre, Beyond Inequalities: Women in Southern Africa, 2000, 213-257.

${ }_{21}$ Cf. F. Butegwa, "Using the African Charter on Human and Peoples' Rights to secure women's access to land in Africa, in R. Cook (ed.), Human Rights of Women: National and International Perspectives, 1994, 495.

22 Tanzania Land Act 1998

23 Southern African Research and Documentation Centre (SARDC) and Women and Law in

Southern Africa Research Trust (WLSA) Beyond Inequalities: Women in Lesotho, 1997, 15.

${ }_{24}$ International Conference on Population and Development, Cairo, UN Doc. A/CONF. 171/ 13, 18 October 1994.

25 SADC Gender and Development Declaration 1997, H(viii).

26 Southern African Research and Documentation Centre Beyond Inequalities: Women in Mauritius, 1997,50 .
} 
information and materials on the human rights of women and children". ${ }^{27}$ Acknowledging the importance of law in social change and the impact of custom in resisting that change, the Declaration borrows from CEDAW by providing that States undertake to engage in "repealing and reforming all laws, amending constitutions and changing social practices which will still subject women to discrimination, and enacting empowering gender-sensitive laws". ${ }^{28}$

This is particularly important because most of the SADG countries have plural legal systems, aspects of which discriminate against women. Indeed some countries' constitutions are in contravention of the SADC Declaration so that the Zimbabwean Constitution continues to ring-fence customary personal law from the non-discrimination provisions in the Constitution thus allowing the continuation of discrimination against women "in matters of adoption, marriage, divorce, burial, devolution of property on death or other matters of personal law". 29

Although the Declaration does touch on the issue of violence against women, providing that states should deal urgently with the increased levels of violence against women, ${ }^{30}$ it was felt that the issue merited particular attention and consequently the SADG Gender Unit drafted an Addendum to the 1997 Declaration focusing on the issue of violence against women. ${ }^{31}$ Using the Vienna Declaration and Programme of Action $^{32}$ as the starting point, ${ }^{33}$ the SADC document identifies violence as including physical, emotional, economic, sexual and psychological violence. ${ }^{34}$ Drawing its inspiration from CEDAW general recommendation number $19^{35}$ and the UN General Assembly Declaration on the Elimination of all Forms of Violence Against Women, $1993,{ }^{36}$ the SADC document identifies the locus of violence as being the home, the community and at the hands of the state. ${ }^{37}$ Specific forms of violence identified include economic deprivation, sexual abuse of children, marital rape, trafficking and forced prostitution and female genital mutilation. ${ }^{38}$ The Declaration notes that the existing measures have proved inadequate in dealing with the issue and indeed in some instances they have been biased against the victims. ${ }^{39}$ To address these shortcomings, the Declaration suggests that measures to be taken to eradicate violence against women and children be grouped under five broad categories: (i) legal measures ${ }^{40}$ (ii) social, economic, cultural and political measures, ${ }^{41}$ (iii) services which will include providing information on services available to

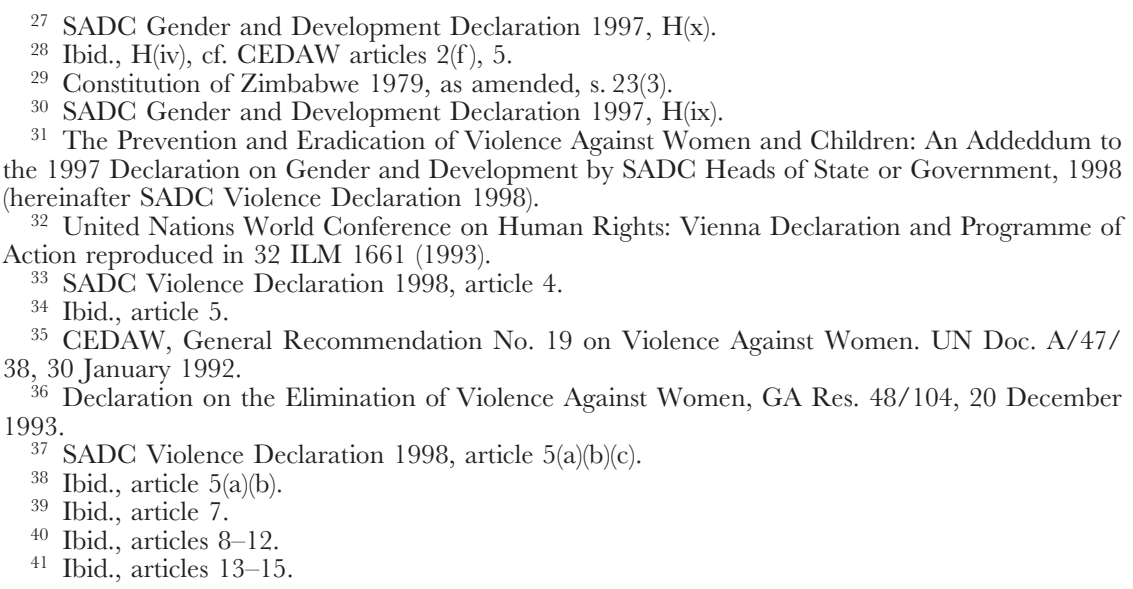


victims of violence, ${ }^{42}$ (iv) measures including education, training and awareness building, ${ }^{43}$ and (v) the requirement that States make adequate provision for these services in their budgets. ${ }^{44}$ Again the SADC approach reflects the integrated $\operatorname{approach}^{45}$ of the UN General Assembly Declaration. The legal measures to be taken include enacting laws that make clear that violence against women is a crime and ensuring the effective enforcement of legislation. The importance of communal dialogue and education to tackle cultural justifications for violence and stereotypes ${ }^{46}$ of the victims of violence is noted. ${ }^{47}$

Recognizing the relatively weak economic position of women and children which increases their vulnerability, the Declaration enjoins States to provide "easily accessible, affordable, and, where possible, free social, and administrative services for the empowerment of women and children victims/survivors of domestic violence". ${ }^{48}$ Ultimately it is acknowledged that the responsibility rests with the State to "adopt(ing) such other legislative and administrative measures as may be necessary to ensure the prevention and eradication of all forms of violence against women and children". ${ }^{49}$

Recent studies of violence against women in the region would seem to show that whilst some states have changed their laws ${ }^{50}$ the problem remains a major stumbling block to the full enjoyment by women of their human rights. ${ }^{51}$ The issue of violence is compounded by poverty, lack of education and access to health facilities which is particularly problematic in light of the HIV epidemic currently engulfing the region. In this regard, it is significant that when asked to identify their national priority areas of concern, ${ }^{52} 12$ SADC countries identified education and training as being the most pressing followed by health (9) with poverty, violence and issues around power and decision-making tied in third place, which when taken together all go to show the inter-connectedness of issues of lack of access to resources and decision-making structures with a high incidence of violence against women.

It remains to consider why SADC and its Declarations are important and what they can tell us about possible future developments in human rights. The first point that needs to be addressed is how important are declarations which are, after all, soft law. Article 18(3) of the African Charter 1980 does not discriminate between declarations and conventions thus suggesting that they are to be considered equally binding: "The State shall ensure the elimination of every discrimination against women and children and shall ensure the protection of the rights of the women and the child as stipulated in international declarations and conventions." The Dow case ${ }^{53}$ shows that that provision can be used to good

\footnotetext{
42 Ibid., articles 16-19.

43 Ibid., articles 20-22.

44 Ibid., article 24.

45 Ibid., article 23. Cf UN General Assembly Declaration on the Elimination of All Forms of Violence Against Women, 1993, articles 4, 5, 6

46 Ibid., article 15.

47 Ibid., article 13

48 Ibid., article 19.

49 Ibid., article 12

${ }^{0}$ Mauritius, Protection from Domestic Violence Act, 1997, Tanzania, Sexual Offences Provisions Act, 1997, Zimbabwe, Sexual Offences Act, 2001.

51 See in particular WLSA Botswana, Chasing the Mirage: Women and the Administration of fustice, 1999, WLSA Malawi, In Search of Justice: Women and the Administration of Fustice in Malawi, 2000.

52 SADC Gender Monitor (1999) at 8.

53 Unity Dow v. Attorney General [1991] LRG (Const) 574.
} 
effect. It is important to acknowledge that the existence of a raft of international instruments has not always guaranteed the enjoyment of human rights in general and women's rights in particular. In this regard, Manji has questioned the reliance on law to deliver justice to African women: "Women have experienced state law as coercive and have deliberately distanced themselves from its control, a fact that undercuts the claim of state law to intervene in every aspect of social life." 54

However for all its constraints, law is a powerful tool that can stimulate change. There are grounds to be hopeful about the prospects of the SADC Declarations bringing about change to the region. Largely this is because of a strong NGO community that includes the powerful Women and Law in Southern Africa Research Trust with offices in seven SADC countries. The NGO lobby is influential in the region with NGOs undertaking research, briefing governments, helping to draft legislation, helping with dissemination efforts and taking test cases to court. Rightly or wrongly women's rights are not considered to be as controversial as multiple-party politics, and so by and large governments are happy to advance, formally, the cause of gender equality. ${ }^{55}$ It is also self-evident that it is easier to get consensus and to iron out differences when there are a few parties participating than when there are many.

FAREDA BANDA

School of Oriental and African Studies

\title{
Amendment of An Indictment: \\ When is it Proper Under Botswana Law?
}

Section 149(1) of the Criminal Procedure and Evidence Act $^{1}$ gives the court a discretion to allow amendments to be made in the indictment or summons at any time before judgment if it considers that such amendment will not prejudice the accused in his or her defence. It provides:

\begin{abstract}
"Whenever, on the trial of any indictment or summons, there appears to be any variance between the statement therein and evidence offered in proof of such statement, or if it appears that any words or particulars that ought to have been inserted in the indictment or summons have been omitted, or that there is any other error in the indictment or summons the court may at any time before judgment, if it considers that the making of the necessary amendment in the indictment or summons will not prejudice the accused in his defence, order that the indictment or summons be amended, so far as it is necessary, by some officer of the court or other person, both in that part thereof where the variance, omission, insertion, or error occurs, and in every other part thereof which it may become necessary to amend."
\end{abstract}

The general rule is that an amendment of a summons should be done before the accused pleads and not during the reading of judgment or delivery thereof. ${ }^{2}$

\footnotetext{
54 A. Manji, "Imagining women's 'legal world': towards a feminist theory of legal pluralism in Africa", (1999) 8(4) Social and Legal Studies 435 at 451.

55 This is not in any way to suggest that women's rights advocates do not experience harassment. Some do. See for example, World Organization Against Torture "Violence against women in Zambia: a report to the Committee against torture", 2002, 247-248.

1 Cap. 08:02 1987 Rev.

2 Hlupekile v. The State (1982) 1 BLR 134.
} 
However, in terms of this section, an amendment may be applied for and granted at any time before judgment.

Notwithstanding the seemingly clear language of section 149(1) the extent of the power to amend conferred by this section has been the subject of conflicting decisions in the High Court of Botswana. The controversy has centred on what constitutes an "amendment" within the subsection. This short comment seeks to analyse the judicial views expressed on the subsection and to ascertain which one is appropriate in the absence of a definitive opinion of the Court of Appeal.

\section{Judicial interpretation of the subsection}

Two views have emerged from the case law. Some judges have been of the opinion that the word "amend" can and does include substituting an existing charge with a new one, while others take the view that where an amendment has the effect of substituting a new charge then it is invalid for it goes beyond the meaning of the word "amend".

An exponent of the second view is Justice Corduff who expressed the view in State v. Lephole ${ }^{3}$ that the section only provides for certain amendments to the particulars to bring the charge into line with evidence. He expressed himself thus:

"Nowhere in the Criminal Procedure and Evidence Act is a court empowered to substitute an entirely new charge for the one to which an accused has pleaded. Section $148^{4}$ provides only for certain amendments to the particulars to bring the charge into line with the evidence subject to certain safeguards."."5

This dictum was made in an appeal where the accused was originally charged with rape but during trial the evidence pointed, or so the presiding magistrate believed, to indecent assault. By section 191 of the then Criminal Procedure and Evidence Act ${ }^{6}$ the court is empowered to find an accused guilty of a lesser offence when charged with rape. The trial magistrate invoked provisions of this section and ordered substitution of the charge of rape by one of indecent assault. The review quashed the conviction, ruling that: "the substitution of a charge of indecent assault was in the present case a grave irregularity". Again in State v. Thekiso, ${ }^{7}$ relying on Zimbabwean case of State v. Moyo, ${ }^{8}$ Cordurf, J., observed that:

"The nature and extent of amendments which are permissible in terms of section 148 are limited and while what can be done in any case will depend upon the particular situation obtaining in that case the general rule is that there must not be a new charge substituted for the one to which the accused pleaded." ${ }^{9}$

In State v. Moyo the accused was charged with and pleaded guilty to stock theft. The prosecutor accepted the plea and tendered to the magistrate a statement of agreed facts. This was read to the accused who, in reply, claimed that he had been compelled by terrorists on pain of death to steal the cattle. The magistrate altered the plea to not guilty. Thereupon the prosecutor advised that he intended

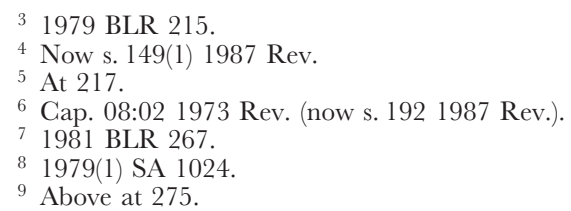


to charge the accused with 14 counts of theft of stock in substitution for the charge before the court. Later the accused appeared before another magistrate, who was aware that a plea of not guilty had been entered. In spite of such knowledge he permitted the prosecutor to put to the accused an entirely new charge which alleged the commission of 14 counts of theft of stock. He was asked to plead, and reiterated that he had stolen the cattle under compulsion. Pleas of not guilty were entered but he was convicted on all counts. On review of the case the issue was whether it was an "amendment" to substitute a charge to which an accused had pleaded with an entirely new one. GubBay, J., observed that an amendment contemplated by section $191^{10}$ "must be an amendment to the charge not the substitution of an entirely new charge" (emphasis mine). The conviction and sentence were overturned.

Similarly in the South African case of $R$ v. Muyekwa $a^{11}$ Lewis, J., held that the substitution of one offence for another was not an amendment. In this case the accused had pleaded guilty to a charge of common assault. During the Crown case and in view of the evidence led by the Crown, the prosecutor applied for an amendment to a charge of assault with intent to do grievous bodily harm. The magistrate allowed the amendment and the accused was convicted on the new charge. Lewis, J., held that the so-called "amendment" of the charge was not an amendment within the meaning of the $\mathrm{Act}^{12}$ but that "it was the substitution of an entirely new charge which was not competent". The interpretation of section 149 preferred by Cordurf, J., was also adopted and followed by Barrington Jones, J., in Monyamane v. The State ${ }^{13}$ where he quashed the conviction and set aside the decision of the trial court on the basis that, "the procedure adopted by the learned magistrate resulted in a serious irregularity". ${ }^{14}$ In that case the trial court had allowed the changing of a charge of indecent assault to that of rape. In his Lordship's view, if during trial the prosecution realizes that the indictment or charge sheet does not cover all the criminal conduct of the accused and wishes to add more charges against the accused, the proper course to be followed is for the prosecutor to seek leave to withdraw the case in terms of the proviso to the then section $149^{15}$ of the Criminal Procedure and Evidence Act, and to lay a fresh charge against the accused.

The contrary view was expressed by HannaH, J., in State v. Kgano. ${ }^{16} \mathrm{He}$ considered that while it is true that for there to be an amendment there must be some existing thing which is the subject of correcting, it does not mean that the substitution of a new charge for the original necessarily falls outside the scope of the word "amend". ${ }^{17}$ Justice Hannal considered the Zimbabwean High Court decisions in the cases of State v. Moyo ${ }^{18}$ and State v. Collet ${ }^{19}$ in which appeals were allowed against an amendment which changed a charge of common assault to one of assault with intent to do grievous harm. He particularly noted the statement by the court in the latter case to the effect that: "not every alteration,

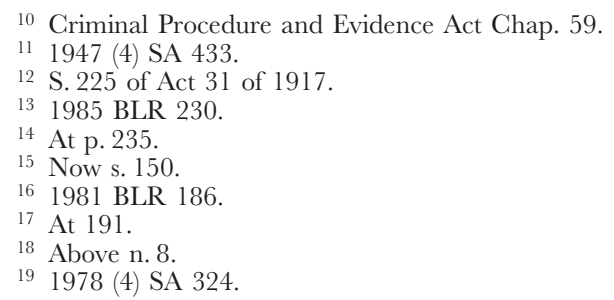


particularly one that causes the complete destruction of the 'existing thing' or its substitution by something else, can properly be deemed an amendment". ${ }^{20}$ His Lordship then considered the English authorities which deal with the court's jurisdiction to amend an indictment. The power is contained in section 5(1) of the Indictment Act of 1915 which reads:

"Where before trial or at any stage of a trial, it appears to the court that the indictment is defective, the court shall make such order for the amendment of the indictment as the court thinks necessary to meet the circumstances of the case, unless having regard to the merits of the case, the required amendments cannot be made without injustice, and may make such order as to the payment of any costs incurred owing to the necessity for amendment as the court thinks fit."

In the English case of $R$ v. Fohal and Lam $^{21}$ the court held that: "in the judgment of this court, there is no rule of law which precludes amendment of an indictment after arraignment either by addition of a new count or otherwise". Similarly, in $R$ v. Radley ${ }^{22}$ three additional counts of conspiracy were added by way of amendment at the end of the prosecution case.

Having considered both the Zimbabwean and South African authorities on the one hand and English authorities on the other, HannaH, J., observed by way of obiter that the interpretation of section 149(1) by the courts in Botswana was to state the position rather too widely. ${ }^{23}$ In this case HANNAH, J., did not conclusively state the position of the law, the case being decided on other grounds. However in Amogelang v. The State ${ }^{24} \mathrm{HannaH}, \mathrm{J}$., confronted the issue head-on. After a comprehensive examination of both Zimbabwean and South African authorities, he came to the conclusion that the power of amendment conferred by section 149(1) includes the power to substitute charges.

The question that arises is why this divergence of opinion in the first place? A closer look at the cases suggests that this has arisen because one view relied on similar provisions in section 5(1) of the English Indictment Act of 1915 and the other on the South African and Zimbabwean equivalents to section 149(1). In his review of the authorities in Amogelang v. The State, HannaH, J., was fortified in his view by saying:

"I am influenced in reaching this conclusion firstly by the similarity between section 149(1) of our Act and section 5(1) of the English Indictment Act, 1915.... Although section 5(1) speaks in general terms of a defective indictment whereas section 149(1) particularises a number of instances when an amendment may be made the section then deals with the matter in a general way stating "or that there is any other error in the indictment or summons'."

He concluded,

"To my mind, in this context, error or defect are of similar meaning and effect and the circumstances in which an amendment may be made are as wide under section $149(1)$ as they are under its English counterpart. I respectfully disagree with the narrow interpretation placed upon the section by CoRdurf, J., in State v. Lephole." 25

\footnotetext{
20 At 191 .

21 (1972) 56 Cr. Appeal R. 348.

22197458 Cr. Appeal R. 394.

23 At 191.

241984 BLR 201

25 At 217.
} 
His Lordship expressed the view that there was a fundamental difference between section 149(1) and its South African and Zimbabwean counterparts. In the South African equivalent the power to amend is in relation to a charge and the Zimbabwean equivalent also refers to a charge whilst under section 149(1) it is in relation to an indictment or a summons. A "charge" consists of statement of offence and particulars thereof while "indictment" refers to the whole document. In his view this difference is a vital one because while the addition of a new charge to an original charge could be said to be filling a gap with something that should already have been there and thus goes beyond the meaning of the word "amend" in the sense of the perfecting or ameliorating of an existing thing, the addition of a new charge does not have the same effect. The indictment or summons has been in existence from the outset of the trial and the addition of a new count cannot be said to be merely the perfecting or correcting the indictment. The destruction of the count by the substitution of another does not destroy the indictment. The concept of indictment is far wider than that of a charge. Using this logical reasoning HannaH, J., arrived at the conclusion that the interpretation to be placed on section 149(1) is that which is placed on its English equivalent.

Once HannaH, J.'s reasoning is appreciated it becomes clear therefore that the South African and Zimbabwean authorities were not immediately relevant for they interpret the word "amend" in the context of a charge and not an indictment.

\section{Which way forward for the Court of Appeal?}

It is likely that we will continue to see conflicting decisions over the interpretation of section $149(1)$ and the loser is the criminal justice system and indeed the accused who are faced with the prospect of like cases being treated differently. The situation calls for intervention by the Court of Appeal.

It is trite law that where the trial court has discretionary power the Court of Appeal is not entitled to substitute its discretion for that of the trial court. ${ }^{26}$ It can only interfere in cases where the trial court had exceeded its jurisdiction or imposed a sentence (in matters relating sentencing), which was not legally permissible for a crime, or has been influenced by facts or motives which were not appropriate for consideration. The question under consideration does not involve the discretionary powers of such courts. What is at issue is whether the word "amend" as used in section 149(1) should be given a narrower or broader meaning, that is, should the word be interpreted to mean not only the perfecting of a charge but also the substitution or addition of new charges? The arguments of HANnAH, J., are to a large extent very attractive taking into account the fact that criminal procedure law in Botswana is fashioned largely after the English law, hence the similarity in the provisions of the local Act and its English equivalent. However, a constitutional argument can be raised to support a narrower interpretation.

The Constitution of Botswana requires that a person charged with a criminal offence must be informed as soon as reasonably practicable, in a language that

26 Ntsompe Shoto and others v. R 1960 HCTLR 1. See also Motsekae Motjolobeka v. R 1955 HCTLR 19. 
he or she understands and in detail, of the nature of the offence charged. ${ }^{27}$ It further requires that the accused be given adequate time and facilities for the preparation of his or her defence. One might therefore ask whether the constitutional requirement is complied with where a person charged with assault and brought to court to answer that charge is instead required to answer to a charge of rape. Similarly, would it be in compliance with the Constitution for a prosecutor during the trial to apply for leave to amend and substitute the offence of assault for rape?

It is submitted that an interpretation which gives a narrower meaning to the word "amend" is more in consonance with the Constitution in that it does not permit surprises for the accused at the trial. Thus the better approach is the one advanced by BARRIngton Jones, J., i.e. that if during the trial the prosecution realizes that the indictment or charge sheet does not cover all the criminal conduct of the accused and wishes to add more charges then the prosecutor must seek leave to withdraw the case and then lay fresh charges against the accused.

K.K. LeBotse

University of Botswana 